\title{
EDUCAÇÃO, SAÚDE E VELHICE: ARTICULAÇÕES PREVALENTES EM PERIÓDICOS
}

\section{EDUCATION, HEALTH AND AGING: LINKAGES PREVALENT IN JOURNALS}

\author{
Luciana Fernandes Paulino, Wânia Ribeiro Fernandes, \\ Vera Helena Ferraz de Siqueira \\ NUTES/UFRJ \\ lufernandesp@yahoo.com.br; verahfs@yahoo.com.br
}

\begin{abstract}
Resumo
O fenômeno de envelhecimento populacional, percebido também no Brasil, torna necessário e urgente, investimentos em pesquisas e práticas que permitam planejar estratégias de atendimento a esta demanda, a qual implica toda a sociedade. Este trabalho investiga os modos como a temática velhice vem sendo abordada e articulada com a educação e a saúde em periódicos científicos que têm a Educação e a Educação em Ciências e Saúde como áreas específicas de investigação, produção e divulgação acadêmico-científicas. O número reduzido de trabalhos encontrados nos fez refletir sobre questões como a pertinência atribuída a este tema na produção cientifica sobre Ensino de Ciências e Saúde e a necessidade de identificar quais focos estão sendo privilegiados, quais questões estão ganhando relevância e quais estão sendo silenciadas nos discursos sobre educação, saúde e velhice.
\end{abstract}

Palavras-chave: educação; saúde; velhice; produção científica.

\begin{abstract}
The phenomenon of population aging, also occurring in Brazil, turns out necessary and urgent to invest into researches and practices that enable planning strategies to meet such demand, which involves the whole society. This paper investigates how the theme of old age appears and how it is being discussed and articulated to education and health in journals that have Education and "Science and Health Education" as specific areas of academic-scientific research, production and dissemination. The few articles identified in our search made us reflect on the relevance given to this theme in Science and Health Education scientific production, and on the need to identify the issues that are being emphasized, the ones that are gaining relevance, as well as those that are being silenced in the discourses on education, health and old age.
\end{abstract}

Key-words: education; health; old age; scientific paper.

\section{Introdução}

O fenômeno do envelhecimento populacional vem se estabelecendo no Brasil em uma progressão rápida e contínua produzindo importantes e múltiplas questões de ordem social, econômica, política e cultural que precisam ser, cada vez mais, consideradas nas pesquisas acadêmicas e na formação profissional. Tendo se instituído 
no Brasil há cerca de 40 anos, o envelhecimento da população brasileira pode ser ainda considerado um fenômeno novo e, como tal traz em seu bojo consideráveis e importantes desafios e demandas (Fernandes, 2010).

Segundo a Organização Pan Americana de Saúde (OPAS) o envelhecimento é um processo, próprio a todos os membros de uma espécie, que ocorre num espaço-tempo de forma seqüencial, individual, acumulativo, irreversível, não patológico, caracterizado pela deterioração de um organismo maduro, de maneira que o tempo o torne menos capaz de fazer frente ao estresse do meio-ambiente e, portanto, aumente sua possibilidade de morte. Para este órgão, os fatores que influenciam e/ou determinam um envelhecimento saudável, com uma boa capacidade funcional e os fatores que aumentam o risco de incapacidade são questões a serem respondidas por pesquisas que incluam a população idosa residente em cada comunidade.

Pode-se perceber que o padrão que vem se configurando na ciência para identificar o "grau de envelhecimento" de uma pessoa ainda é associado à "degeneração" orgânica. Segundo Canguilhem (2009), a sociedade ocidental tende a confundir saúde com juventude, permitindo, assim que seja construída uma correlação entre doença e velhice. Esta ótica, que concebe a velhice como uma espécie de doença, parece direcionar as ações tidas como de educação e promoção de saúde, assim como as pesquisas, no campo do envelhecimento humano, que cada vez mais se fixam no que seriam as causas e determinantes das doenças no envelhecimento. Cabe, portanto, considerar que não é possível pensar em uma resposta única e pronta às questões referentes ao fenômeno de envelhecimento, na medida em que este se dá de forma complexa, com múltiplos significados e construções. Para alguns autores, o envelhecimento é tido como uma experiência vivenciada de forma não homogênea, permeado por fatores subjetivos e também sociais, históricos e culturais. O próprio conhecimento científico, também atravessado por esses fatores, desempenha um papel fundamental na atribuição de significados a essa questão, à medida que justifica, explica e legitima determinadas práticas e atitudes em relação à velhice (NERI, 1991; COUTO \& COUTINHO, 2003-2004). Assim, o discurso científico pode e deve contribuir na reconstrução de seu dizer, buscando a inversão dos significados hegemônicos sobre o envelhecimento para a elaboração de um dizer que inaugure uma nova história da velhice em nossa sociedade (op.cit.).

Por fim, para entendermos as ações de educação e saúde no país faz-se necessário compreender que, historicamente, a saúde nunca ocupou lugar central dentro da política do Estado brasileiro. Ela sempre foi deixada na periferia do sistema, tanto no que diz respeito à solução dos problemas de saúde que afligem a população, quanto na destinação de recursos direcionados ao setor. Somente nos momentos em que 
determinadas endemias ou epidemias se apresentam como importantes, em termos de repercussão econômica ou social, é que elas passam a ser alvo de uma maior atenção por parte do governo, até serem novamente destinadas a um plano secundário, quando, aparentemente, seus índices ficam mais baixos. No âmbito da saúde da pessoa idosa o cenário não tem sido diferente.

\section{Metodologia Adotada}

Considerando o objetivo de investigar trabalhos científicos que abordaram questões referentes à velhice, nos campos da Educação e Educação em Ciência e Saúde, estabelecemos como parâmetros de busca nove termos/expressões com o intuito de proporcionar amplitude de cobertura ao tema que movimenta a pesquisa. São eles: "idoso(s)"; "idosa(s)"; "velho(s)"; "velha(s)"; "velhice"; "envelhecimento"; "terceira idade"; "gerontologia"; "geriatria".

Os periódicos consultados foram selecionados segundo critérios de credibilidade junto à comunidade científica, tendo sido tomadas em conta, ainda, as missões pretendidas por cada um. Desse modo, foram eleitas revistas das áreas da Educação em Ciências e Saúde, e da Educação, em geral. Entendendo a impossibilidade de esgotarmos o leque de opções que se abre a partir dos critérios acima estabelecidos, destacamos os seguintes periódicos (quatorze no total): Cadernos de Saúde Pública; Interface - Comunicação, Saúde e Educação; Revista de Saúde Pública; Ciência \& Educação; Educação e Pesquisa; Educação \& Sociedade; Cadernos de Pesquisa; Revista Brasileira de Pesquisa em Educação em Ciências (RBPEC/ABRAPEC); Pesquisa em Educação em Ciências (Ensaio); Enseñanza de las Ciencias; Revista Electrónica de Enseñanza de las Ciencias (REEC); Revista Ciências e Saúde Coletiva (ABRASCO); Revista Brasileira de Educação (ANPED); Revista Educação e Sociedade. Os materiais selecionados foram consultados em ambiente virtual, parte deles através da base de dados SciElo cuja interface de busca favorece o ágil cruzamento de termos. Além dos periódicos consultados a partir da referida base, foram consideradas, também, as páginas eletrônicas de revistas não incluídas na SciElo, quais sejam: RBPEC/ABRAPEC; Ensaio; Enseñanza de las Ciencias e REEC, bem como complementações de busca nas páginas dos periódicos não contemplados inteiramente pela base SciElo em toda a extensão do corte temporal por nós arbitrado. São elas: Interface; Ciência \& Educação; Cadernos de Pesquisa; ANPED.

Estabelecemos como parâmetro temporal, para o inicio da investigação, o ano de 1999, correspondente à implementação da Política Nacional de Saúde do Idoso (PNSI), importante medida no cenário das políticas públicas relativas à área do envelhecimento, 
tendo sido cobertos todos os números dos periódicos selecionados até abril de 2009 (período final de nosso levantamento).

Para cruzar com os nove termos/expressões acima citados, utilizamos os termos "Educação, Prevenção e Promoção em/de/da/para a Saúde", a fim de captarmos a totalidade de trabalhos referentes à este campo que abordasse questões sobre velhice. Com esse procedimento, conseguimos rastrear um número modesto de artigos, considerando o volume de produção desta área. Além disso, cabe ressaltar que tais achados não se deram de forma homogênea para todos os periódicos consultados, uma vez que das quatorze fontes de consulta, somente quatro continham artigos pertinentes à proposta deste trabalho. São eles: Interface - 3 artigos (2005, 2006 e 2007); Cadernos de Saúde Pública - 2 artigos (2004 e 2007); Revista Saúde Pública - 2 artigos (2003 e 2006); Ciência e Saúde Coletiva - 2 artigos (2004 ambos).

Antes de discutirmos os resultados deste levantamento, cabe abordar aspectos importantes relativos à educação, sobretudo no campo da saúde, e este, no que concerne às questões e demandas relativas à velhice.

\section{Educação e Saúde: questões, impasses e deslocamentos}

A educação tem incorporado as questões de saúde através de um deslocamento que responsabiliza os indivíduos por suas doenças, minimizando a participação do sistema político social no processo de adoecimento do sujeito.

A Educação em Saúde surge no Brasil no início do século XX, como um processo formador de condutas saudáveis com discursos e práticas calcados em modelos coercitivos. Esta perspectiva, hegemônica no século passado, caracterizava-se por ações verticais que preconizavam a adoção de novos comportamentos, pela população, tais como ações corretas de higiene corporal, ambiental e alimentar como parar de fumar e vacinar-se dentre outros. Deste modo, o acesso à saúde é entendido como responsabilidade e esforço individual, partindo do princípio de que cabe às pessoas, informadas sobre os riscos de adoecimento, a responsabilidade de adotar um novo estilo de vida mais saudável. Desconsiderou-se, neste processo educativo, que lida com histórias de vida, as crenças, valores e a própria subjetividade do sujeito que exige ações estruturadas sócio-culturalmente.

Os resultados obtidos nesse processo não foram muito favoráveis; duas características são importantes nesse contexto. A primeira delas é que as ações "educativas" eram realizadas com o público feminino, historicamente responsável pelo cuidado da família, lembrando que a escolarização das mulheres era considerada, naquele momento histórico, desnecessária no desempenho das tarefas domésticas; a segunda característica é a inadequação ou dicotomia entre a cultura popular e a dos 
"doutores" da saúde, gerando um grande conflito entre a informação técnica e as convicções sócio-culturais daquele grupo social.

A Educação em Saúde no Brasil, como uma política populacional, é recente. Teve suas primeiras ações na chamada fase higienista, ocorrida entre 1903 até 1920, caracterizando-se por ações impositivas onde o uso da força policial era comum. As primeiras idéias de Educação Popular, baseadas no pensamento de Paulo Freire, que afirma ser a Educação sempre um ato político que não se resume na reprodução do sistema vigente, começam a influenciar alguns trabalhos na área da saúde, calcados nas idéias de conscientização e libertação. Entretanto, o Golpe Militar de 1964 interrompe drasticamente toda e qualquer ação desenvolvimentista e inovadora. Somente com o final do regime militar, em 1985, algumas ações localizadas, desenvolvidas por grupos específicos, são identificadas, não refletindo, porém as políticas públicas institucionais adotadas.

Machado (1997) destaca que as aproximações entre os Ministérios da Educação e da Saúde caracterizam-se pela falta de organização e continuidade sendo, portanto, insuficientes para mudar o panorama epidemiológico do país, refletindo uma ausência de vontade política dos seus dirigentes.

Importante destacar que todas essas abordagens continuam tratando o sujeito como o "alvo", como o objeto a ser transformado e modificado. As discussões não se dirigem para que se pensem as desigualdades sociais, a falta de saneamento ou abastecimento de água potável, muito menos a má distribuição de renda, geradora de pobreza e miséria como fatores participantes do adoecimento populacional. As ações tidas como de Educação em Saúde, preconizadas nos livros didáticos de ciências ou pelas políticas públicas de saúde visam sempre uma ação específica "para", alguma coisa ou algum segmento. O foco está na "ponta", em alguém que supostamente não consegue agir adequadamente. Responsabiliza-se o sujeito pelos seus males e adoecimentos, incute-se nas pessoas a noção de que cabe somente a ela agir de forma a obter saúde, como se esta fosse algo passível de ser adquirido com "passos e ações programadas". Tal como bulas, as orientações são dadas: exercite-se assim, alimente-se de tal modo, durma tantas horas, controle suas emoções. Assim, "educar em saúde" com freqüência é entendida como dar informação, preconizar modos de viver.

\section{A Educação em Saúde no Envelhecimento}

A questão da educação em saúde no envelhecimento, no Brasil, como um campo, ainda sofre pela incapacidade política de implementar atividades educativas metodologicamente planejadas. O conhecimento técnico-científico na área ainda é precário, por parte das autoridades responsáveis pela consolidação de políticas de saúde. 
Em geral, as ações identificadas como de educação em saúde são fundamentadas em modelos biomédicos de intervenção (Candeias, 1997).

Especificada na atualidade como "um campo que objetiva desenvolver nas pessoas um sentido de responsabilidade, como indivíduo, membro de uma família e de uma comunidade, para com a saúde, tanto individual, como coletivamente"*, a Educação em Saúde neste enfoque, prescinde de qualquer metodologia sistematizada, desde que seu objetivo primeiro seja alcançado, qual seja desenvolver a noção de responsabilidade de saúde nos sujeitos. Contudo, para que se consiga desenvolver tais "noções de responsabilidade"* necessário que os sujeitos, agentes e pacientes deste processo, saibam, conheçam, identifique e tenham informação que os permitam pensar soluções práticas, cabíveis para sua realidade. ${ }^{1}$

Seria necessário que a educação assumisse o compromisso de estimular na população o senso crítico, a capacidade de reflexão sobre consequiências das ações individuais na coletividade. A responsabilidade de todos com o meio ambiente, gerando um entendimento da realidade e complexidade do processo saúde-doença, considerando que a comunidade produz condições de saúde/doença, mas que somente através do desenvolvimento da cidadania, seríamos capazes de cobrar das autoridades competentes ações determinantes para este processo, como saneamento básico para as residências, construção de aterro sanitário, dentre outras.

No referente à formação acadêmico-profissional, a Câmara de Educação Superior do Conselho Nacional de Educação ${ }^{2}$, ao orientar as novas diretrizes curriculares dos cursos de graduação da área da saúde recomenda que estas devem:

"estimular o abandono das concepções antigas e herméticas das grades (prisões) curriculares, de atuarem, muitas vezes, como meros instrumentos de transmissão de conhecimento e informações, e garantir uma sólida formação básica, preparando o futuro graduado para enfrentar os desafios das rápidas transformações da sociedade, do mercado de trabalho e das condições de exercício profissional".

Tais deliberações apontam para a necessidade de haver um processo educacional em saúde com atividades sistematicamente planejadas, visando alcançar um efeito concreto sobre a saúde.

As práticas educacionais em saúde para a terceira idade não diferem muito das voltadas para as outras faixas etárias. Em geral elas acontecem em forma de “campanhas" onde, através de cartazes e palestras, algumas atitudes são preconizadas e

1 * www.bireme.br. Biblioteca Virtual em Saúde, acessado em 28/07/2007.

${ }^{2}$ CNE/CES - Parecer n. 1.133/2001 - aprovado em 07/08/2001. 
prescritas como saudáveis. Durante tais "campanhas", a população é conclamada a caminhar, alimentar-se de forma "balanceada", vacinar-se, fazer atividade física, enfim responsabiliza-se pelo quanto de saúde ele(a) obterá, ficando o sistema político com a função apenas de deflagrar tais "movimentos". Assim, "educar em saúde" passa a significar dar informação, alertar para algumas questões (Fernandes, 2010).

\section{A Velhice em trabalhos sobre Educação, Prevenção e Promoção de Saúde}

Tratando-se especificamente do levantamento realizado, tomando por base a leitura dos resumos dos trabalhos contemplados, foi possível identificar apenas nove produções que correspondessem ao nosso recorte, mostrando tratar-se de um tema ainda muito pouco exploração pela comunidade científica do campo da Educação em Ciências e Saúde.

Dentre as palavras-chave de maior relevância para este artigo, o termo "promoção da saúde" esteve presente em todos os nove artigos levantados, sendo um deles "promoção da saúde do idoso". Três produções se utilizaram do termo específico "saúde do idoso". Ainda no campo específico da saúde, contou-se um trabalho com o termo "saúde coletiva" e um intitulado "comportamento saudável". Em contrapartida, apenas dois trabalhos continham o termo "educação em saúde", sugerindo que a temática vinculada à velhice e envelhecimento é contemplada com mais ênfase pelo campo da saúde do que pela educação. O termo "prevenção de/da/em/para saúde", no entanto, não esteve presente em nenhuma produção.

Por ser alvo de freqüentes confusões e mal entendidos faz-se necessário diferenciar os termos "prevenção" e "promoção". Segundo Czeresnia (2003), estudiosa da área, as ações preventivas podem ser entendidas como intervenções orientadas a evitar o surgimento de doenças específicas ou diminuir sua incidência/prevalência. A base do discurso preventivo seria o conhecimento epidemiológico moderno e seu objetivo, o controle da transmissão de doenças infecciosas. Os projetos de prevenção em saúde consistiriam na divulgação de informações científicas e de recomendações normativas de mudança de hábitos. A promoção de saúde define-se, tradicionalmente, segundo esta autora, de forma mais ampla que a prevenção, uma vez que não se referem a medidas diretivas a uma determinada doença ou desordem, mas servem para aumentar a saúde e o bem-estar gerais; como estratégias de promoção, considera-se a transformação das condições de vida e trabalho, que conformam a estrutura subjacente aos problemas de saúde, segundo uma abordagem mais intersetorial. Quanto à Educação em Saúde, de acordo com o Scientific Group on Research in Health Education, da OMS, é seu objetivo "desenvolver nas pessoas o senso de responsabilidade pela sua própria saúde e pela saúde da comunidade a qual pertençam e a capacidade de participar da vida comunitária de uma maneira construtiva". Entende-se, assim, que 
para a OMS, cabe à Educação em Saúde promover no sujeito tanto o senso de responsabilidade individual quanto a comunitária (Fernandes, 2010).

Com relação à formação acadêmica dos(as) autores dos artigos, quase todos(as) (que foram informadas) eram da área da saúde (com exceção de um profissional do Serviço Social), assim como os departamentos os quais estavam vinculados. Estes trabalhos foram escritos, de uma forma geral, por Profissionais de Fisioterapia, Odontologia, Terapia Ocupacional e Enfermagem, dos Departamentos de Saúde Pública, Medicina, Enfermagem, Nutrição, Ciências da Saúde, Promoção e Assistência à Saúde e outros afins. Entendemos que a ênfase na área da saúde pode se dever ao fato da maior parte das produções encontradas sobre esta faixa etária estar publicada em periódicos de Saúde Pública, conforme apontado acima, o que sugere que questões relativas à velhice, sejam vistas como algo prioritariamente pertencente a este campo.

Foi possível identificar concepções diferenciadas de saúde nos resumos estudados. Foram poucos os trabalhos que apresentaram uma discussão sobre saúde levando em consideração apenas o aspecto biológico. A maior parte dos trabalhos considerou a saúde em sua relação com outros aspectos da vida dos sujeitos, como o social, econômico, demográfico e o subjetivo; com relação a este último, foram mencionados fatores como felicidade, bem-estar, confiança, qualidade de vida e saúde mental. Deste segundo grupo, dois trabalhos consideram claramente a interdisciplinaridade, além de um outro, de levantamento bibliográfico, que utilizou como critério de busca, "trabalhos multitemáticos".

Cabe ressaltar que foi na a Conferência Internacional sobre Promoção de Saúde, em Otawa (1986), que a saúde passou a ser considerada enquanto a qualidade de vida resultante de um complexo processo, condicionado por diferentes fatores, como alimentação, justiça social, ecossistema, renda, educação, dentre outros. No Brasil, a conceituação ampla de saúde está presente no Relatório Final da VIII Conferência Nacional de Saúde. A idéia de promoção de saúde preconiza, desse modo, o fortalecimento da capacidade do indivíduo e do coletivo para lidar com a multiplicidade dos condicionamentos da saúde. Assim, este conceito se propõe ir além de uma aplicação técnica/normativa; visa o fortalecimento da saúde por meio da possibilidade de escolha; considera a utilização do conhecimento com discernimento de atentar para diferenças e singularidades. (Czeresnia, 2003)

No entanto, mesmo tendo se percebido uma prevalência de produções que discutissem saúde segundo uma visão mais ampla e complexa, foram freqüentes os trabalhos que traziam a perspectiva de mudança de comportamento dos sujeitos da pesquisa; destes, quase todos adotaram uma metodologia interventiva em suas pesquisas, segundo os próprios, "intervenção educacional", "oficina para treinamento de 
memória", "grupos de promoção à saúde", "processo de reminiscências" e "grupos focais". Em número menor, foram identificados trabalhos que contemplavam a perspectiva de controle de taxas, por exemplo, de massa óssea e de desempenho da memória; houve ainda, neste universo, trabalhos que lançaram mão de uma análise comparativa, sendo alguns desses, através de exames e testes (além de entrevista).

Todos os trabalhos empíricos, a maior parte contemplada, teve como sujeito da coleta de dados o próprio idoso; apenas um abordou outra categoria (no caso, adolescentes). As poucas produções que não faziam parte deste contexto foram apresentadas em forma de trabalho teórico, relato de experiência e levantamento bibliográfico. Este resultado nos remete a seguinte questão: será que a velhice e o envelhecimento dizem respeito somente ao sujeito que envelhece, ou, no máximo, a quem convive e/ou cuida dele? Quanto aos procedimentos metodológicos, somente um trabalho apresentou um caráter claramente quantitativo (utilizando-se de percentuais para apresentar seus resultados) e dois se mostraram declaradamente qualitativos. Os demais trabalhos deixaram dúvidas quanto à forma de abordagem: alguns destes não mencionavam sua metodologia de análise enquanto outros não citavam seus resultados. Verifica-se, portanto, a necessidade de maior clareza e objetividade na apresentação dos artigos (resumos) de forma a facilitar a compreensão dos leitores, quanto à proposta destes trabalhos.

Cabe observar que todos os trabalhos levantados foram publicados após o ano de 2003, período em que em foi instituído o Estatuto do Idoso - Lei n. 10.741, em $1^{\circ}$ de outubro de 2003, sugerindo sua importância e influência na visibilidade às questões e demandas apontadas por este grupo etário e sua repercussão nos diferentes campos de conhecimento e intervenção, assim como para a sociedade de um modo geral.

\section{Considerações Finais}

A análise e discussão dos artigos levantados nos permitiu observar que, apesar da prevalência da concepção de saúde se apresentar segundo uma visão mais abrangente, a qual extrapola a dimensão biomédica, considerando outros aspectos da vida, como o social, econômico, cultural e subjetivo, mostrou-se muito presente a tendência prescritiva no âmbito comportamental, ou seja, direcionada mudança das atitudes e formas de vida dos sujeitos envolvidos, e não de uma forma mais crítico-reflexiva.

Tal constatação sugere a permanência de uma herança do campo biomédico, de caráter mais intervencionista, freqüentemente acrescido do movimento de responsabilização e/ou culpabilização desses sujeitos por sua condição de saúde. Esta visão minimiza ou negligencia aspectos importantes a serem considerados também no campo da educação em saúde, como as experiências de vida e os valores construídos e em construção, ou seja, sua singularidade; são instâncias que estão sujeitas a constantes 
deslocamentos ao longo da vida, mas não de forma obrigatória e instantânea, a partir das informações e intervenções das "autoridades do saber".

Nesse sentido, tomando como base o entendimento sobre prevenção e promoção de saúde apresentados por Czeresnia, os artigos considerados apresentam uma visão mais voltada para a prevenção do que para a promoção de saúde, a despeito das palavras-chave mencionadas.

Em concordância com esta autora, reconhecemos o desafio de se traduzir informações geradas na produção de conhecimento científico em ações que promovam efetivamente transformações de âmbito social, ambiental e das condições de vida e saúde dos sujeitos. Tais desafios, conclui, não se resolvem com aplicação de novos modelos, assim como a questão da educação não se resolve limitando-se a informação e capacitação técnica.

Assim, acreditamos ser possível entender esta dinâmica de forma mais complexa, reconhecendo a necessidade de estendermos e aprofundarmos esta discussão neste e em outros campos de saber.

\section{Referências}

Candeias, N.M. Conceitos de educação e de promoção em saúde:mudanças individuais e organizacionais. Rev. Saude Pública. 31 (2): 209-13, 1997.

Canguilhem, Georges. O normal e o patológico.RJ: Forense Universitária, 2009.

Couto, A.L.A. \& Coutinho, M.L.R. Reflexões acerca do discurso científico sobre o envelhecer. In: Série Documenta / UFRJ. Programa de Mestrado e Doutorado em Psicossociologia de Comunidades e Ecologia Social - Eicos / Cátedra Unesco de Desenvolvimento Durável - Vol. IV, nº 14-15, 2003-2004.

Czeresnia, Dina. O Conceito de Saúde e a Diferença entre Prevenção e Promoção. In: CZERESNIA Dina; Freitas C. M. (Org.). Promoção da saúde: conceitos, reflexões, tendências. Rio de Janeiro: Editora Fiocruz, 2003.

Fernandes, W.R. Educação em saúde da pessoa idosa: discursos oficiais e subjetivações no Município de Lages, SC. Tese[doutorado], NUTES/ Universidade Federal do Rio de Janeiro, 2010, 191p.

Machado, MLT Educação em saúde: concepções teóricas e práticas em um serviço público de saúde. São Carlos: UFSCar [Dissertaçãode Mestrado], 1997.

Neri, A.L. Envelhecer num País de Jovens. Significados de Velhos e Velhice Segundo Brasileiros Não-Idosos. Campinas, SP: Edit da Unicamp, 1991.

\section{Sites:}


Scielo: http://www.scielo.br/scielo.php?lng=pt

Estatuto do Idoso / LEI No 10.741/093:

http://www.planalto.gov.br/ccivil/leis/2003/110.741.htm

Política Nacional de Saúde do Idoso - Portaria 1395/GM:

http://www.ufrgs.br/3idade/portaria1395gm.html

Conferência Nacional de Saúde On-Line. Educação em Saúde. Histórico, Conceitos e Propostas. Ministério da Saúde. Diretoria de Programas de Educação em Saúde.

http://www.datasus.gov.br/cns/datasus.htm.

Estatuto do Idoso - Lei N. 10.741/03:

http://www.planalto.gov.br/ccivil/LEIS/2003/L10.741.htm

\section{Autores:}

Luciana Fernandes Paulino: doutoranda do Programa de Pós-Graduação Educação em Ciências e Saúde - NUTES/CCS/UFRJ.

lufernandesp@yahoo.com.br

Wânia Ribeiro Fernandes - doutora pelo Programa de Pós-Graduação Educação em Ciências e Saúde - NUTES/CCS/UFRJ.

waniafer@hotmail.com

Vera Helena Ferraz de Siqueira: professora associada Coordenadora do Laboratório de Linguagens e Mediações, docente do Programa de Pós-Graduação Educação em Ciências e Saúde - NUTES/CCS/UFRJ.

verahfs@yahoo.com.br 